\title{
An Exploration of Universal Design Principles in a Special Education Teacher Preparation Course: Part I
}

\author{
Mary Gozza-Cohen \\ Widener University, Chester, PA
}

\begin{abstract}
Universal Design for Learning (UDL) involves using multiple and flexible means for: presenting content, engaging students with the content, and allowing students to demonstrate their understanding through expression and apprenticeship. Learning preferences, general strengths and interests, and areas of need are considered for all students, including students with disabilities. This is done, in part, to maximize student engagement and ultimately student learning. Learning is doing. Teaching pre-service special education teachers about UDL by incorporating UDL principles in the design and instruction of teacher preparation courses would, ideally, facilitate a better understanding of these guiding principles. This study examined the efforts made by an instructor to incorporate UDL principles during a previously taught course. Additionally, this study provides suggestions to improve UDL methodologies and student assessments for future courses.
\end{abstract}

\section{Introduction}

Current U.S. legislation, such as No Child Left Behind (NCLB) [1] and the Individuals with Disabilities Education Act (IDEA) [2], includes high expectations for student learning outcomes and for educators to adequately teach children from varying cultures and with differing abilities (students with and without disabilities and second language learners) and learning preferences (e.g., auditory, visual, tactile). Effectively teaching in an inclusive classroom requires skills that go beyond content knowledge and traditional pedagogical practices that are primarily effective for a core group of students who would learn regardless of the methodology. The principles of Universal Design for Learning (UDL) can address a variety of learning preferences, interests and student needs [3].

UDL aims to reduce the barriers to learning that currently exist in many classrooms by assisting teachers in their understanding of how students learn and how today's digital technology may provide support or challenging opportunities for students who may otherwise be disengaged. [3]. The ultimate goal is to increase student engagement and successful learning. The U.S. Department of Education's Office of Special Education Programs (OSEP) recognized the need to support educators and has funded a number of initiatives that specifically address UDL.

The OSEP initiatives involving UDL include the Center for Applied Special Technology (CAST), the ACCESS Project through Colorado State University, Center for Implementing Technology in Education (CITEd), Ensuring Access Through Collaboration and Technology (EnACT), and the National Instructional Materials Accessibility Standard (NIMAS) [4]. Another OSEP funded initiative is the IRIS Center at Vanderbilt University in Nashville, $\mathrm{TN}$, and Claremont Graduate University in Claremont, CA [5]. This web-based initiative was created specifically for preservice teacher preparation and professional development on evidence-based teaching practices, including UDL. The IRIS Center module on UDL was the fourth most visited module in 2014 yielding 50, 437 visits with " $75.3 \%$ of all colleges and universities with a special education option using the IRIS resources" [5].

Faculty in preservice special education teacher preparation programs are challenged to use a variety of resources to teach effective, evidence-based practices. Higher education faculty are continuously seeking innovative ways to prepare future educators to meet the educational needs of the diverse learners they will likely encounter one day when they have a classroom of their own [6]. Ideally, higher education faculty would be able to incorporate UDL methodologies while teaching the teacher preparation courses necessary for accreditation and teaching licensure.

\section{Special education teacher preparation}

Evans, Williams, King and Metcalf (2010) described UDL implementation in three undergraduate special education teacher preparation courses [6]. The authors described the course activities that related to the UDL principles and methods in which they demonstrated them in their 
own teaching. For example, for some of the content the students viewed a video or digital demonstration of a UDL/direct instruction lesson plan being implemented in a classroom and discussed what worked and what did not to assess how the lesson might be changed in the future [6]. Students also completed UDL lesson plans or units that required the inclusion of low tech and high tech methods and materials and the identification of barriers and related solutions [6]. This particular study did not report student performance measures and studies in higher education reporting such measures are limited. Edyburn, when discussing the implementation of UDL in K-12 settings suggests: "statements such as 'UDL is just good teaching' serve to preserve the status quo, which marginalizes low-performing students. We must find ways to define and measure implementation of UDL in order to discern when it is being implemented and when it is not" [7].

One might argue that defining and measuring understanding and implementation of UDL principles in preservice special education teacher preparation programs might be equally as important [6]. New teachers' in-depth understanding of UDL principles is essential if they are expected to implement these practices in the future. There are a number of ways to assess the depth of student understanding that should ultimately deepen over time. For example, during the freshman year of a special education teacher preparation program, the lowest level of understanding is all that might be expected of the students.

\section{Assessing student understanding}

Although student understanding will be explored in part two of this study, this section discusses multiple methods for assessing student learning. Traditionally, multiple choice and short answer/essay tests are used for assessment purposes. In teacher preparation courses, lesson plan development, implementation and presentations are also used, but the evaluation of courses for evidence of UDL practices may be more complex. Other methods of assessing student learning, UDL course development and implementation include journals, course assignments, and the Structure of the Observed Learning Outcomes (SOLO) Taxonomy that has been used to systematically assess the levels of complexity of student understanding and learning and may be useful for evaluating written assignments $[8,9,10]$. The SOLO Taxonomy is one method to rate students' understanding of the principles of UDL over time. As students learn, their responses become increasingly more complex; the SOLO Taxonomy evaluates understanding and learning both quantitatively (i.e., the number of correct points made) and qualitatively (i.e., whether the points made inter-relate) [9]. The SOLO taxonomy is not content-dependent and consists of five levels with each student artifact scored from 1 to 5 using the hierarchy [11]. This taxonomy will be utilized and discussed in Part II in a future study along with other related assignments.

\subsection{Journals and assignments}

The assessment of private journal entries and individual assignments that involve initial thoughts about a new topic, participation in a related activity or series of activities and ending with a follow up reflection is one way of assessing student understanding of content. The assignment/journal prompts need to be carefully crafted in order to elicit higher order, more complex thinking. Evaluating the responses can be done using rubrics or taxonomies, such as the Structure of the Observed Learning Outcomes Taxonomy.

Teaching practices and course design have a direct impact on student learning. Biggs and Tang's Constructive Alignment used to analyze and organize what instructors do to meet course objectives is the tool used in this study to explore the expected learning outcomes and the activities and assessments used to foster and assess student understanding.

\section{Research design and questions}

This study involved a qualitative case-study design through the examination of course design, materials and assessments for a special education teacher preparation undergraduate course and is part 1 of a 2-part study. This study (part 1) examined the course for evidence of Universal Design for Learning principles using, in part, Constructive Alignment. A description of part 2 of this research (student performance and perceptions) is included in the Future Research section on page 7.

\section{Context for current study}

This study involved an examination of the implementation of UDL principles in a course with twenty undergraduate sophomore students in a dual teacher certification program in general and special education pre-kindergarten-grade 4 (general education) and pre-k through grade 8 special education program in a private university in the northeast United States. The students participated in a course on technology integration and Universal Design for Learning. Part II of this study is currently underway and will be presented in a subsequent paper that will assess student understanding of UDL principles using, in part, using the SOLO Taxonomy 
to assess student work and through student interviews.

\section{Course description}

The course used in this study provided learning experiences that help develop knowledge of technology integration and its ability to support students with diverse abilities, including students who are English language learners (ELL). Students acquire instructional technology strategies that support differentiated practices and can be applied to the construction of lesson and activity plans, and instructional goals and objectives that incorporate content, pedagogy, and developmental considerations consistent with state learning standards. Participants had opportunities to create assessments utilizing a variety of technologies. Additionally, the course assisted students' understanding of the various types of adaptive and assistive technologies used in special education.

After several class sessions and assignments, the instructor/researcher informally assessed student understanding of the UDL principles. Unsatisfied with the assessment results, the instructor sought to deepen student understanding using additional resources and activities. Part I of this study assessed the instructor's implementation of UDL teaching practices as one way to model UDL concepts. This was completed using Bigg's Constructive Alignment to assess the alignment of the intended learning outcomes, the teaching and learning activities and the assessments used to evaluate student understanding. Next, this study used this information to qualitatively use this information to assess the 'fit' with the UDL Principles.

\section{Constructive Alignment for assessing course content}

To assess and plan courses for evidence of UDL practices and opportunities to teach UDL, Biggs and Tang's Constructive Alignment was used for the purpose of the first phase of this study. Constructive alignment involves the identification of Intended Learning Outcomes (ILOs), Teaching/Learning Activities (TLAs) and Assessment Tasks (ATs) [11].

Constructive alignment requires that the ILOs contain "statements...indicating the level of understanding and performance they are expected to achieve as a result of engaging in the teaching and learning experience" [11]. TLAs are "The verbs the students need to enact" and ATs are "...the evidence for the achievement of the ILO's" [11].

Aligning ILO's, TLA's and AT's with the principles of UDL allows examination of the presence of UDL and meaningful course activities and assessments aligned with learning outcomes. For the purpose of this study, Biggs and Tang's Constructive Alignment will be used, in part, to assess the use of UDL principles in an undergraduate special education teacher preparation course.

\section{Results}

The course structure and documents in the undergraduate course were examined for evidence of the effective use of the principles of UDL, including, in part, multiple methods of presenting content (representation) to students, multiple methods of student engagement with the content and multiple methods for allowing students to demonstrate their understanding of the content (action and expression). The Constructive Alignment was first used to examine the ILOs, TLAs and ATs. The results are presented in the sections that follow.

\subsection{Intended Learning Outcomes}

\begin{tabular}{|l|}
\hline \multicolumn{1}{|c|}{ Intended Learning Outcome 1 } \\
Develop web-based technologies that will facilitate \\
communication with parents, support active student \\
learning and explore assistive technology internet \\
resources.
\end{tabular}

Figure 1. ILO 1, TLAs and ATs 


\section{Intended Learning Outcome 2}

Develop knowledge of technology integration and its ability to support struggling students and motivate their learning.

Teaching and Learning Activities

Chapter readings, videos and lectures

IRIS Peabody Modules:

1. Universal Design for Learning: Creating a Learning Environment that Challenges and Engages All Students

2. Assistive Technology: An Overview Assistive Technology Training Online (ATTO) site Interactive poll, webquest and digital story creation Use of Word for student learning

CAST.org and National Center for UDL websites

In-class discussions

Individual and collaborative small group activities

Assessment Tasks

Private content and activity related reflective journal entries

UDL lesson plans, teacher webpage creation

Webquest and digital story creation

Technologies for student and teacher use projects

Research paper

Note: assessments include grading rubrics

Figure 2. ILO 2, TLAs and ATs

\begin{tabular}{|c|}
\hline $\begin{array}{c}\text { Intended Learning Outcome } 3 \\
\text { Develop knowledge of learning theory and pedagogy } \\
\text { that supports differentiated instruction. }\end{array}$ \\
Teaching and Learning Activities \\
Chapter and other readings, videos and lectures \\
IRIS Peabody Modules: \\
1. Universal Design for Learning: Creating a \\
Learning Environment that Challenges and \\
Engages All Students \\
Assistive Technology: An Overview \\
CAST.org website resources \\
National Center for UDL website \\
In-class discussions \\
Individual and collaborative group activities \\
\hline$\quad$ Assessment Tasks \\
Private content and activity related reflective journal \\
entries \\
Lesson plan development \\
Teacher webpage creation \\
Webquest creation and digital story creation \\
Technology for student use project \\
Technology for teaching project \\
Technology for productivity \\
Research paper \\
Note: assessments include grading rubrics
\end{tabular}

Figure 3. ILO 3, TLAs and ATs

\section{Intended Learning Outcome 3}

Develop instructional technology strategies that can be applied to the construction of lesson and activity plans, set instructional goals and objectives that incorporate content, pedagogy and developmental considerations, consistent with state standards.

Teaching and Learning Activities

Chapter readings, eTextbook videos and lectures Other web-based videos on content Lesson plan development IRIS Peabody Modules:

1. Universal Design for Learning: Creating a Learning Environment that Challenges and Engages All Students

2. Assistive Technology: An Overview

Assistive Technology Training Online (ATTO) Buffalo Project website

CAST.org website resources

National Center for UDL website

Webquest creation and digital story creation

Technology for student use, for teaching project

In-class discussions, Individual and collaborative small group activities

Assessment Tasks

Private content and activity related reflective journal entries

Lesson plans

Webquest creation, digital story creation

Technologies for student use; teaching

Research paper

Note: assessments include grading rubrics

Figure 4: ILO 4, TLAs and ATs

\section{Intended Learning Outcome 5}

Create a variety of assessments using several different technologies

Teaching and Learning Activities

Chapter readings, eTextbook videos and lectures IRIS Peabody Modules:

1. Universal Design for Learning: Creating a Learning Environment that Challenges and Engages All Students

2. Assistive Technology: An Overview

Assistive Technology Training Online (ATTO) site Interactive web-based poll

Teacher webpage and Webquest creation, use of Word CAST.org website resources

National Center for UDL website

In-class discussions, individual and collaborative small group activities

\section{Assessment Tasks}

Private content and activity related reflective journal entries

UDL lesson plans

Teacher webpage creation

Webquest creation and digital story creation

Technologies for student use; teaching; productivity

Research paper

Note: most of above assessments include grading rubrics

Figure 5: ILO 5, TLAs and ATs 


\subsection{Universal Design for Learning Evidence}

The figures that follow include brief descriptions of the three main principles of UDL, examples and evidence from the course in this study.

\section{Representation - UDL Principle 1}

Presenting information and course content in multiple formats so that all students can access it. IRIS Module Examples: Provide alternatives for accessing information (e.g., visual, auditory). Provide or activate background knowledge in multiple ways (e.g., pre-teaching concepts, using advanced organizers)

Evidence from course in the study

Provide options for comprehension

+ Readings, Videos, Lectures, Connections to field

placement experiences

Provide options for language, mathematical expressions, and symbols

+ Multimedia, IRIS Modules and videos that included captioning and in some instances, alternate language translations.

Provide options for perception

+ eTextbook with built in features for modifying display, text-to-speech capabilities, other digital materials with similar options, video with captioning for demonstration, personal connections - individual preferences gleaned from beginning of semester survey data, conversations and private journal entries.

\section{Figure 6: UDL principle 1}

\section{Action and Expression - UDL Principle 2}

Allowing students alternatives to express or demonstrate their learning. IRIS Module Examples: Provide options for responding (e.g., keyboard instead of pen to complete a writing assignment). Provide options for completing assignments using different media (e.g., text, speech, film, music)

\section{Provide options for executive functions}

+ Checkpoints for projects, Journals on progress, concerns, questions

Provide options for expression \& communication

+ Options for assignments - select tools of interest to use for various projects, Options for presentation of work, Graduated levels of support using checkpoints

Provide options for physical action

+ Vary the methods for response - used text-based journals only. Could have used options for video responses, Optimize access to tools and assistive technologies - no one needed AT and access to tools was the focus of the class - happened naturally

Figure 7: UDL Principle 2

\section{Engagement - UDL Principle 3}

Stimulating students' interests and motivation for learning in a variety of ways. IRIS MODULE Examples: Provide options that increase the relevance and authenticity of instructional activities (e.g., using money to teach math, culturally significant activities). Provide options that encourage collaboration and communication (e.g., peer tutoring)

\section{Self-Regulation}

Evidence from course in the study

+ Rubrics for self and peer assessment. Reflection journals: what worked, what did not work, what might be changed, reflection on learning.

\section{Sustaining effort and persistence}

+ Multiple resources on same topic with varying levels of complexity. Option to work in pairs. Provided feedback with opportunities to modify work. Provided extra lab time for 1:1 support and feedback.

Recruiting interest

+ Opportunities to choose topic of interest and mode of delivery. Utilized beginning of semester survey to get to know students. Use of private journals, anonymous surveys and class discussions for student feedback topics of interest to explore further. Student choice for research topic paper.

\section{Figure 8: UDL principle 3}

\section{Discussion}

Figures 1 through 5 provide an analysis of the teaching and learning activities and assessments for each of the intended learning outcomes (course goals) from the Constructive Alignment tool. As noted, the course utilized an eTextbook that contained links to videos, private electronic contentand course-related journal reflections, a variety of other electronic documents, websites, and videos, along with individual and small group activities and whole class discussions. The Constructive Alignment analysis revealed an adequate alignment of the learning outcomes as stated in the syllabus for the course with the course activities and assessments; however, there is always room for improvement.

Upon further examination of the ILO's, requirements for higher-level cognitive processes could be specified in the syllabus for this course. Discussing and analyzing our progress and seeking specific input from students at the beginning of the semester could also prove beneficial to both the instructor and the students. One of the important goals in teacher preparation programs is to facilitate teacher-like thinking from our students. Eliciting student input on the design of course activities and assessments from the start of the semester would encourage active participation in their learning. This does not suggest that students would design all activities and assessments, but an essential component of meaningful learning involves student 
interests and preferences. In addition to the beginning of the semester survey where I inquire, in part, about student preferences, and interests, it might be beneficial to have students review the syllabus and specific course documents and provide input as an initial assignment for discussion. The analysis using the Constructive Alignment tool has resulted in these and other thoughts regarding course modifications for future semesters. There was also great value in completing this analysis prior to examining the course for evidence of the principles of Universal Design for Learning, as it required a more in-depth review of the course.

The IRIS Center module titled: Universal Design for Learning: Creating a Learning Environment that Challenges and Engages All Students [12] was used as an assignment for students to complete after an informal assessment of their understanding of the UDL principles revealed unsatisfactory results. This module utilizes the UDL principles to teach about UDL and is an excellent resource for this content. As with all modules on the IRIS site, it began with a challenge, asked for the participants' initial thoughts and proceeded to provide $8-10$ web pages with wellorganized information on the content that included text-based, video, and audio resources with transcripts for the audio and video materials. The site also provides materials and forms that can be printed and used by the participant for future reference. It is a rich resource that students anecdotally found deepened their understanding of UDL. The UDL assignment was also the inspiration for the current study.

Another key element to a true UDL designed lesson or course that was not previously mentioned is the consideration of individual differences. In K-12 school settings, a UDL Barrier Analysis is used to consider student characteristics, preferences and disabilities (learning, physical and sensory disabilities). Teachers are provided information about students with disabilities so they may provide modifications or accommodations to meet their learning needs. In higher education in the U.S., students with disabilities must self-disclose; faculty are not automatically notified about students with disabilities in their courses. For students with physical and some sensory (visual or hearing impaired students), the presence of a disability is often more obvious. Learning disabilities (also referred to as a hidden disability) are much harder to detect. However, the completion of my beginning of semester survey provides students the opportunity to voluntarily disclose this information. Although I did not complete a barrier analysis for my class, I maintained a good rapport and safe environment that allowed them to freely speak with me regarding any issues they had with learning. Figures 6 through 8 include the three UDL principles with a brief description with IRIS Module examples and evidence of each of the principles as reflected in the course materials, activities and assessments.

Figure 6 includes the methods used in the course related to UDL Principle 1 - Representation. Examination of the course learning materials and activities revealed multiple methods for presenting information to students. At one point during the semester, an informal assessment of student understanding of the UDL principles revealed a very basic level of understanding. The addition of the IRIS Module on UDL was added and a cursory review of the formal assessment after completion of the module revealed positive gains. Background knowledge must also be assessed and not assumed. The use of private journals or initial thoughts assignments for this purpose can be very revealing and save faculty time and effort in the long run.

The UDL Principle 2 - Action and Expression results for the course are shown in Figure 7. This involves allowing students alternatives to express or demonstrate their learning and, generally, students were permitted to do so. There were some assignments where this would not be possible, such as completing a lesson plan using the required format. Repeated checks on student progress were embedded in the course structure. Toward the end of the semester when multiple technology projects were required, students were asked to provide a progress report either verbally or in writing. Question and answer and work sessions were provided frequently due to the nature of the work involved for the course.

Figure 8 includes evidence from the course on UDL Principle 3 - Student Engagement that includes self-regulation, sustaining effort and persistence, and recruiting interest. Rubrics were utilized for all of the assignments and some of the assignments included self and peer assessments. This was used to assess and teach about tools use for self-regulation. The private journal was also used as a place to communicate with students and to help keep them on track. Multiple resources were used on the same topic with varying levels of complexity along with option to work in pairs. Feedback was provided with opportunities to modify work along with extra lab time for 1:1 support. Anecdotally, students appeared to appreciate this level of support, particularly given the nature of the course that involved a good deal of project work. Students were also encouraged to create projects on topics that they knew well and would enjoy teaching. This served, in part, to keep them engaged.

\subsection{Summary}

This article examined a special education teacher preparation course for evidence of UDL teaching practices. Reflection on the course design, materials, and assessments revealed the strengths of the course and areas for improvement. There are numerous 
examples where multiple methods of representation, engagement and action and expression are evident. Truly effective implementation of the UDL principles involves a thorough examination of student responses to these practices. This should include student performance on related activities and perceptions of the course design, structure, activities, assessments and their own learning. Additionally, Universal Design for Learning is not as simple as learning about and demonstrating good teaching practices. UDL also involves a knowledge of student interests, strengths, needs and preferences for learning and knowing how to effectively meet the needs of all students in the most effective manner. It may be most advantageous for preservice special education teachers to develop the knowledge and skills necessary to effectively implement UDL in their future teaching if they are taught using these principles in their preparation program.

\section{Suggestions for future research}

As previously mentioned, this study was part 1 of a 2-part study that examined the use of UDL principles in a special education teacher preparation undergraduate course. Part 2 will involve an assessment of student understanding of UDL principles based on archived related course activities. Students will be asked to volunteer to participate in an interview and/or focus group to obtain a deeper understanding of the impact of the course activities, assessments and their understanding and perceptions of UDL. Future research should also involve a systematic evaluation of additional teacher preparation courses and be extended to higher education in general. If faculty across campuses utilized more of the principles of UDL in their teaching, a greater number of student needs will be met by changing how think about teaching and learning.

\section{Implications for practice}

Effectively incorporating UDL practices in all courses will allow faculty to practice what we preach and become facilitators of student learning. If preservice teachers are assessed on their depth of understanding of UDL throughout their teacher preparation program, the assessment data could be used to inform higher education faculty teaching practices each semester. Most importantly, if students have a thorough understanding of UDL and have opportunities to teach using these principles during their fieldwork and student teaching, they will be highly prepared to use these principles in their future classrooms to meet the needs of all students, including students with disabilities.

\section{References}

[1] No Child Left Behind Act of 2001,20 U.S.C. $\$ 6301$ et seq., 2001.

[2] Individuals with Disabilities Education Improvement Act of 2004, P.L. 108-446. 20 U.S.C. $\S 1400$ et seq. (2004).

[3] D. Rose, A. Meyer, Y. Strangman and G. Rappolt, Teaching every student in the digital age: Universal design for learning, Association for Supervision and Curriculum Development, Alexandria, VA, 2002.

[4] U.S. Department of Education, Office of Special Education. Funded Centers that Support UDL. Retrieved: https://www.osepideasthatwork.org/UDL/support.asp

[5] IRIS Center Fast Facts (2014). Retrieved May 10, 2015 from http://iris.peabody.vanderbilt.edu/wp-content/ uploads/misc_media/misc_pdfs/IRIS_fast_facts.pdf

[6] C. Evans, J.B. Williams, L. King and D. Metcalf. "Modeling, Guided Instruction, and Application of UDL in a Rural Special Education Teacher Preparation Program", Rural Special Education Quarterly, ACRES, Kentucky, 2010, pp 41-48.

[7] D.L. Edyburn. "Would you recognize Universal Design for Learning if you saw it? Ten propositions for new directions for the second decade of UDL", Learning Disability Quarterly, Hammil Institute on Disabilities, Texas, 2010, pp 33-41.

[8] J.B. Biggs, "Individual differences in study processes and the quality of learning outcomes", Higher Education, Springer, Netherlands, 1979, pp 381-394.

[9] J.B. Biggs, "Approaches to the enhancement of tertiary teaching", Higher Education Research and Development, pp 7-25, 1989.

[10] M. Delfino and D. Persico, "Online or face-to-face: Experimenting with different techniques in teacher training”, Journal of Computed Assisted Learning, pp 351365, 2007, Doi:10.1111/j.1365-2729.2007.00220.x.

[11] J.B. Biggs, J. B. and K.F. Collis Evaluating the Quality of Learning: The SOLO Taxonomy, Structure of the Observed Learning Outcome. Academic Press, New York, 1982.

[12] The IRIS Center for Training Enhancements. (2009). Universal Design for Learning: Creating a Learning Environment that Challenges and Engages All Students. Retrieved on May, 10, 2015 from http://iris.peabody.vanderbilt.edu/udl/ 